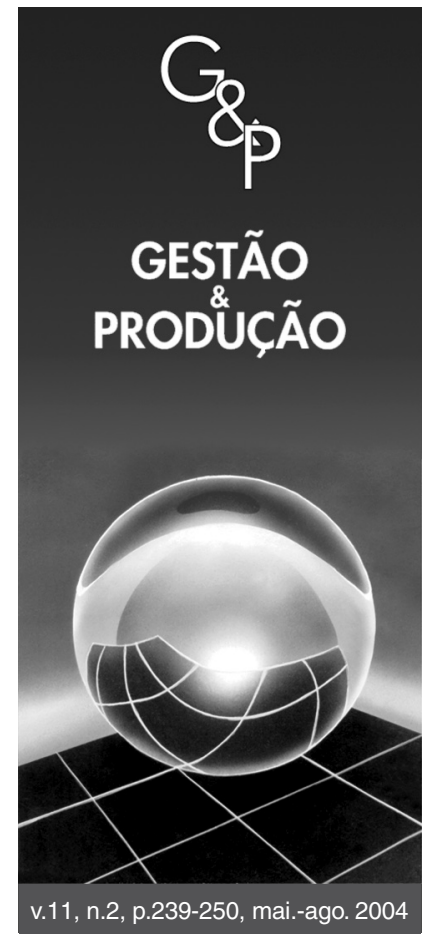

\title{
SELEÇÃO DOS OBJETIVOS FUNDAMENTAIS DE UMA REDE DE COOPERAÇÃO EMPRESARIAL
}

\author{
José Roberto Tálamo \\ Marly Monteiro de Carvalho \\ Departamento de Engenharia de Produção, Escola Politécnica da USP, \\ Av. Prof. Luciano Gualberto, travessa 3, n³80, CEP 05508-900, São Paulo, SP \\ e-mail: marlymc@usp.br; jrtalamo@ hotmail.com
}

\section{Resumo}

A abertura dos mercados criou uma nova ordem econômica, baseada fundamentalmente na estruturação de novas formas de organização da produção, com ênfase na competitividade e na inovação tecnológica. Novas formas de organização industrial são rapidamente incorporadas à cultura das empresas, como resposta aos novos desafios de mercado. Uma das formas de organização que merece destaque é a Rede de Cooperação Empresarial - RCE. Neste trabalho, pretende-se analisar a formação de uma RCE do setor eletroeletrônico, estudando sua configuração. Destaca-se neste artigo, o processo de estabelecimento dos objetivos fundamentais da RCE pelos empresários, cuja estrutura de prioridades utilizou o AHP (Analytic Hierarchy Process) como ferramenta de apoio à decisão.

Palavras-chave: Rede de Cooperação, análise hierárquica do processo - AHP, pequenas e médias empresas - PME.

\section{Introdução}

A abertura dos mercados criou uma nova ordem econômica, baseada fundamentalmente na estruturação de novas formas de organização da produção, com ênfase na competitividade e na inovação tecnológica. Novas formas de organização industrial são rapidamente incorporadas à cultura das empresas, como resposta aos novos desafios de mercado.

Uma das formas de organização que merece destaque é a Rede de Cooperação Empresarial - RCE, um agrupamento de empresas que buscam objetivos comuns, geralmente localizados na esfera da lucratividade, ou seja, a busca da sobrevivência. Este tipo de organização empresarial tem apresentado experiências de sucesso no Brasil.

O sucesso competitivo de RCE's em diversos países, como é o caso das redes de pequenas e médias empresas nos distritos industriais italianos, as redes keiretsu no Japão ou as empresas de alta tecnologia do Vale do Silício, despertaram o interesse acadêmico para o estudo de suas diversas configurações (Williamson, 1985; Segenberger e Pyke, 1990; Storper e Harrison, 1991; Porter, 1998; Belussi e Arcange- li,1998; Porter e Stern, 2001; Carvalho e Laurindo 2003).

Neste trabalho, pretende-se analisar a formação de uma RCE do setor eletroeletrônico, estudando sua configuração segundo os modelos de Storper e Harrison (1991) e Belussi e Arcangeli (1998). Destaca-se, neste artigo, o processo de estabelecimento dos objetivos fundamentais da RCE pelos empresários, cuja estrutura de prioridades utilizou o AHP (Analytic Hierarchy Process), como ferramenta de apoio à decisão (Saaty, 1991).

\section{Redes de Cooperação}

A formação de redes de cooperação tem impactos na produtividade e escala, na inovação das empresas envolvidas, além de permitir, em alguns casos, a formação de novos negócios (Porter, 1998). Nesse sentido, as empresas que se unem em redes conseguem apropriar-se destes ganhos, obtendo vantagens competitivas. Este autor argumenta que o sucesso de uma RCE está no equilíbrio entre competição e cooperação. Vários autores têm utilizado o termo co-opetição (co-opetition) para 
denominar este equilíbrio (Porter, 1998; Levy et al., 2003).

Segundo Loebbecke e Van Fenema (1998), existem três forças de co-opetição: sinergia, nivelamento e impacto reverso-negativo (negative reverse-impact - NRI). A sinergia representa a adição potencial de valor, que a troca de informação pode proporcionar para as partes envolvidas. O nivelamento é a capacidade daquele que recebe a informação em aumentar seu valor, explorando o conhecimento compartilhado além da relação de cooperação. Por último, o NRI determina quanto o uso da informação pela parte receptora reduz o valor da parte emissora da informação (fator inibidor da co-opetição).

Segundo Carvalho e Laurindo (2003), as ações conjuntas (join actions), obtidas por esforço deliberado e consciente das empresas da rede, podem ser de dois tipos: cooperação entre empresas (por exemplo, compartilhar equipamentos) e grupos de empresas organizadas por associações ou consórcios, como de exportação. Estas ações conjuntas de cooperação podem ser horizontais (entre competidores) e verticais (entre elos da cadeia). Quando a dimensão geográfica também está presente, são observadas, além das ações conjuntas, a existência de externalidades incidentais oriundas da aglomeração, com impacto nos custos de transação. Neste artigo, não se pretende discutir a dimensão geográfica, enfatizando-se a questão do projeto de configuração da RCE.

Lundvall (1992) argumenta que, sendo o recurso fundamental na economia moderna o conhecimento, o processo mais importante é o aprendizado. Este autor destaca que a atividade inovadora é um processo intrinsecamente social e coletivo e depende, fundamentalmente, das interações entre os agentes, chamado de aprendizado pela interação (learning-byinteraction). Para entender este processo no interior das redes, é preciso entendê-lo como socialmente inscrito, levando-se em consideração seu contexto institucional e cultural. Carlsson et al. (2002) argumentam que compreender a dinâmica destas interações, ou seja, entender a robustez, flexibilidade, habilidade de gerar mudanças e rapidez de resposta às mudanças ambientais, é um aspecto essencial neste tipo de análise.

As informações e a transmissão dos conhecimentos no interior da rede de cooperação fluem por processos de aprendizado formais ou informais. Por outro lado, as ações conjuntas de cooperação que permitem reduzir riscos, aumentar escala e compartilhar recursos, como já comentado, tendem a ter um processo de decisão mais estruturado e formalizado.

A formação de uma rede de cooperação pode apresentar entraves à medida que surgem assimetrias, com o aparecimento de uma empresa-líder, que passa a exercer forte influência nas estratégias das demais empresas da rede, inibindo as ações conjuntas de cooperação.

Storper e Harrison (1991) formularam uma taxonomia de redes, as quais podem ser classificadas conforme abaixo:

- Rede sem assimetrias (all ring-no core): Esta estrutura configura-se por uma relação entre iguais e sem qualquer espécie de hierarquia entre os agentes;

- Rede levemente assimétrica com empresa coordenado- ra (core-ring with coordinating firm): a estrutura apresenta algum grau de hierarquia, com leve assimetria entre os agentes participantes do sistema, por causa de certa influência sistemática de uma empresa coordenadora, porém limitada e não determinante da sobrevivência das empresas participantes do sistema. Os limites da empresa coordenadora residem na sua incapacidade de realizar as atividades que são realizadas pelos demais participantes do sistema;

- Rede assimétrica com empresa líder (core-ring with lead firm): a estrutura apresenta forte hierarquização, com assimetrias entre a empresa líder e os demais agentes. Nesta estrutura, as ações das outras empresas do sistema dependem das estratégias da líder, tendo sua sobrevivência condicionada a ela; e

- Rede hierárquica (all core): nesta estrutura, as atividades são assumidas por uma grande empresa verticalizada, quase não configurando uma rede de empresas.

Segundo Carvalho et al. (2003), esta taxonomia representa um continuum que vai da ausência de hierarquia (all ring-no core) à hierarquia plena (all core). Na definição de Humphrey e Schmitz (2000), as duas configurações assimétricas intermediárias poderiam ser chamadas de redes qua$s i$-hierárquicas. E a rede hierárquica, segundo Williamson (1979), seria classificada como integração vertical.

O modelo de rede, escolhido pelas empresas envolvidas na rede de cooperação ora apresentada, é a Rede sem Assimetrias, ou seja, sem assimetrias ou qualquer modo de hierarquia.

Outra visão importante na concepção da rede foi proposta por Belussi e Arcangeli (1998), que apresentam uma tipologia, em que os eixos da análise são as formas de aprendizagem e a freqüência da interação entre as empresas locais, resultando em três tipos de redes: estacionárias (steady-state), retráteis - reversíveis e evolucionárias.

As redes estacionárias caracterizam-se pela divisão do trabalho entre as empresas locais, predominando as relações de caráter estático, ou seja, incapazes de gerar novos conhecimentos e formar competências coletivas. No segundo tipo de rede, as retráteis-reversíveis, as empresas apresentam relações mais frequientes e dinâmicas, capazes de incorporarem novos conhecimentos e adaptarem-se de acordo com as exigências da demanda. O terceiro e último tipo de rede, a evolucionária, apresenta um intenso aprendizado por interação e formação de competências coletivas. Além do aprendizado por interação, as empresas focalizam-se em suas competências essenciais (core competences) e mantêm interações muito freqüentes com as outras empresas da rede (Prahalad e Hamel, 1990).

A Figura 1 ilustra este modelo, no qual, quanto mais freqüentes e estáveis forem as relações entre as empresas da rede, maior o aprendizado pela interação e maior a capacidade de geração de vantagens competitivas.

\section{Análise Hierárquica do Processo - AHP}

O Método da Análise Hierárquica - Analytical Hierarchic Process (AHP), método de apoio à decisão, criado por Saaty 


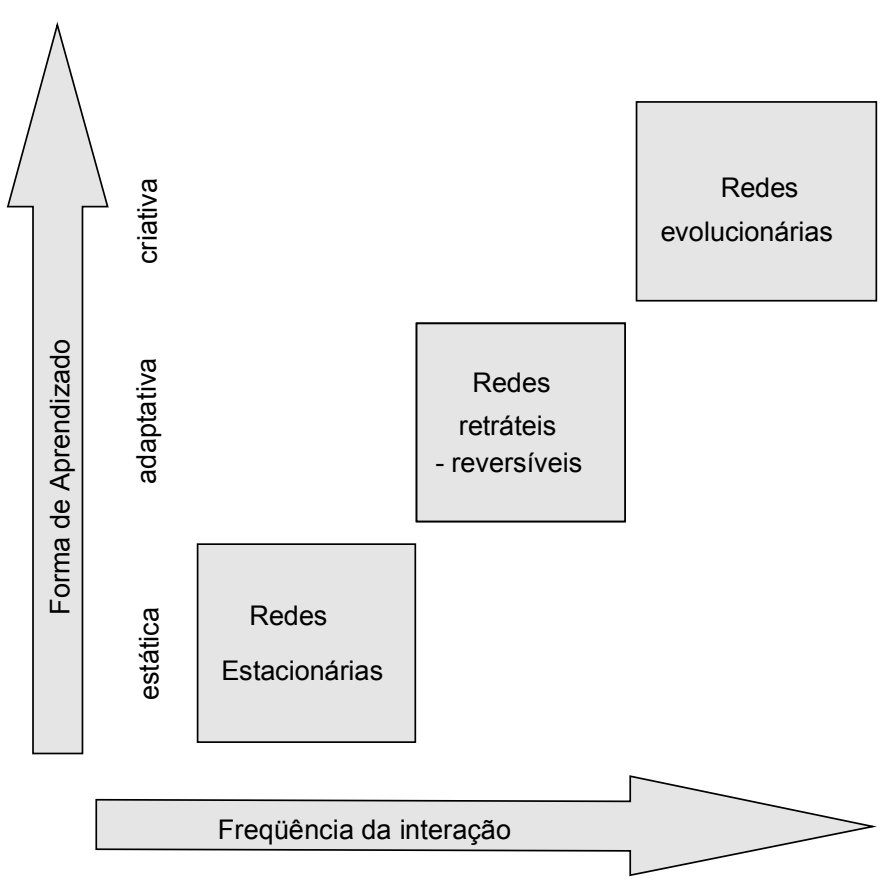

\section{Figura 1. Tipologias de rede (Adaptado de Belussi e Arcangeli, 1998).}

na década de 70, usa uma estrutura hierárquica para representar um problema de decisão, apropriado a uma equipe de decisores frente a problemas pouco estruturados. Os membros da equipe definem o objetivo e desenvolvem critérios para satisfazer o objetivo, fazendo julgamentos e a priorização de multicritérios. Além disto, o método estabelece os pesos por meio do cálculo das prioridades como autovetor, o que permite ao tomador de decisões medir a consistência de suas decisões.

Este método tem sido empregado para situações de: definição de prioridades, avaliação de custos e benefícios, alocação de recursos, mensuração de desempenho, avaliação ou pesquisa de mercado, determinação de requisitos, decisões estratégicas etc. (Morita et al., 1999).

Segundo Laurindo et al. (2002), o modelo usa julgamentos comparativos de pares de fatores, estudando sua consistência e sua validade, de forma a não deixar de levar em consideração a ambigüidade decorrente da associação de números a julgamentos.

Segundo Carvalho (1997), apesar do amplo e crescente espectro de aplicações do AHP, existem algumas restrições quanto ao uso deste método, que podem ser aprofundadas nos trabalhos de Dyer (1990a; 1990b) e Saaty (1990). Um dos problemas apontados no AHP é a quantidade de comparações paritárias necessárias, que cresce muito rapidamente com o tamanho da matriz destas comparações. Existem técnicas que permitem reduzir este número de comparações paritárias. Outra crítica freqüente a este método é a reversão de ordem, ou seja, a alteração das alternativas dominantes em função da inclusão ou exclusão de alternativas irrelevan- tes (Morita et al., 1999).

Graças às características do método, julgou-se adequada sua utilização para estruturar a tomada de decisão dos empresários da RCE. As entrevistas para a obtenção das notas nas comparações paritárias foram feitas com os empresários das empresas envolvidas na rede de cooperação, conforme será detalhado a seguir.

\section{Metodologia}

A proposta inicial desta análise foi a estruturação de uma Rede de Cooperação Empresarial, com pequenas e médias empresas (PME's) do segmento eletroeletrônico. A escolha deste segmento industrial deu-se em função da pouca vivência nacional em organização de empresas na forma de redes e, principalmente, em segmento de tecnologia intensiva, no qual projetos e desenvolvimentos assumem caráter estratégico.

Para isto, foram contatadas trinta e cinco empresas de pequeno e médio porte, todas integrantes do segmento de instrumentação científica. No contato inicial, foram apresentados, aos empresários responsáveis, os conceitos básicos de estruturação de uma rede de cooperação empresarial, suas vantagens e desvantagens. Após os contatos preliminares, verificou-se que onze empresas eram apenas distribuidoras de equipamentos importados, não fazendo parte de nosso objetivo primordial, que é a estruturação de uma nova forma de produção. Das vinte e quatro empresas restantes, em duas não foram finalizados os contatos, duas empresas sofreram restrição de outras já consultadas e cinco não manifestaram interesse na participação da RCE.

Quatorze empresas manifestaram interesse na participação e formação da RCE. Estas empresas, eventuais integrantes desta RCE, atuam na fabricação de equipamentos e instrumentos eletrônicos, destinados aos mais variados setores da economia nacional, tais como, construção civil, indústria eletroeletrônica, distribuição de energia elétrica e manutenção industrial.

Após a estruturação da rede de cooperação empresarial, ainda em estágio inicial, formalizou-se a aceitação da divulgação dos nomes dos futuros integrantes da RCE. Foram questionados pontos fortes e fracos de cada empresa, e os aspectos nos quais havia ou não interesse no compartilhamento. Após uma reunião inicial, três empresas detalharam os pontos solicitados, conforme as Tabelas 1 e 2 .

Com os dados iniciais, foram estabelecidos os princípios fundamentais da estruturação do problema, que é:

1. A discussão e o caminho a ser adotado pelo grupo, para se obter o consenso para a busca da solução do problema comum a todos; e

2. Dada a natureza holística desta análise, o problema foi dividido em partes e áreas menores, em função da área de atuação dos participantes (tecnologia intensiva), diversidade de porte das empresas, e diferentes graus de especialização dos participantes, a fim de se determinar os aspectos que mais interferem no problema como um todo. 
Tabela 1. Itens em que há e em que não há interesse de compartilhamento de atividade.

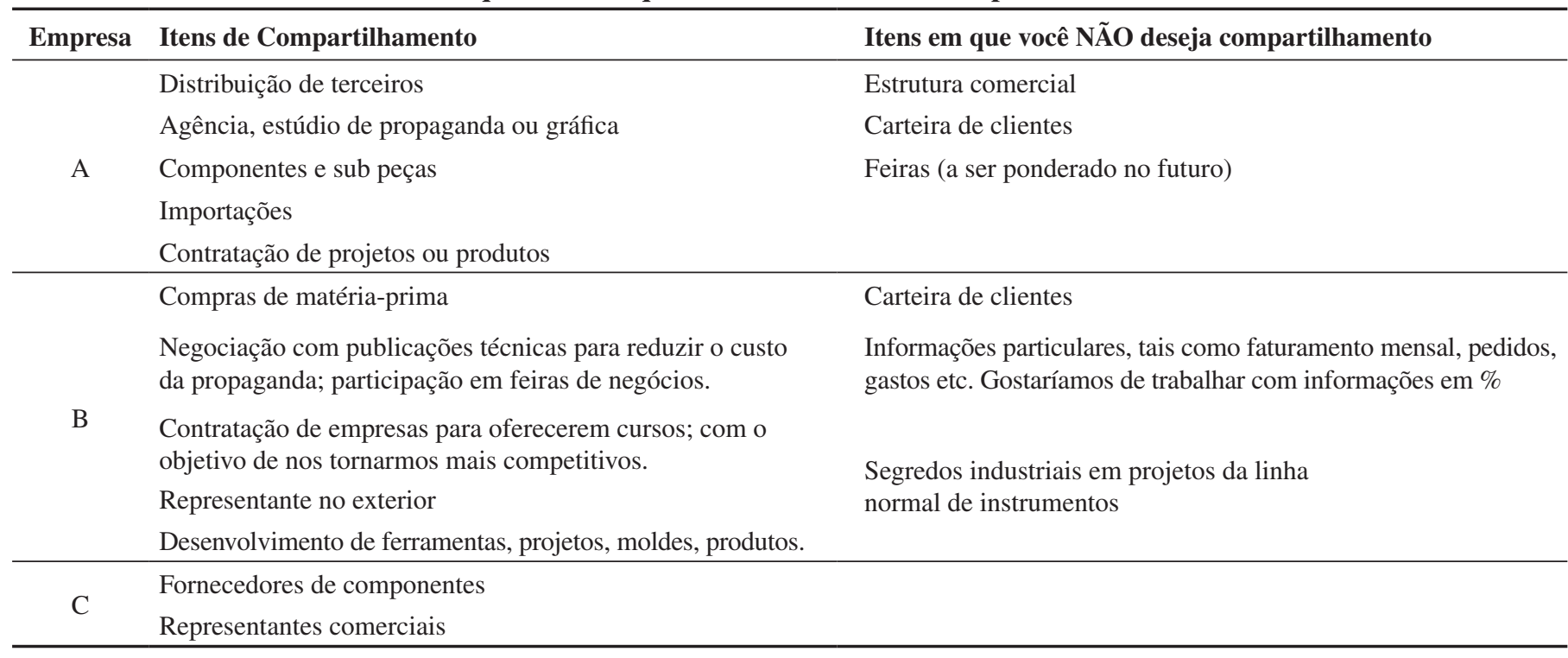

Tabela 2. Pontos fortes e fracos de cada empresa - respostas espontâneas.

\begin{tabular}{cll}
\hline Empresa & Pontos Fortes & Pontos Fracos \\
\hline & Qualidade & Unidade fabril pequena \\
& Flexibilidade e agilidade & Dependência técnica \\
A & Estoque de acabados & Necessidade de novos produtos na linha \\
& Expansão comercial contínua & Pouco capital disponível \\
& Acordos com o exterior & \\
\hline \multirow{3}{*}{ B } & Experiência - alto nível de conhecimento na área & Dificuldade em recrutar e selecionar vendedores \\
& Disponibilidade para execução de projetos especiais & $\begin{array}{l}\text { Capacidade produtiva pequena } \\
\text { Dificuldade na aquisição de matéria-prima por causa } \\
\text { da quantidade }\end{array}$ \\
& Tempo de atuação no mercado: 21 anos & Falta de estrutura para exportar \\
& Grande carteira de clientes & Capacidade produtiva totalmente utilizada \\
\hline & Ampla variedade de produtos & Precisamos de mais representantes \\
& Desenvolvimento de software em ambiente windows & Participação em feiras e eventos \\
& Facilidade em desenvolver protótipos em pouco tempo & Exportação de equipamentos
\end{tabular}

Uma análise complexa, como é o caso, dificilmente poderia ser simplesmente decomposta em problemas menores, com respostas combinadas em uma resposta comum. De acordo com Saaty (1994) o conhecimento e a experiência individuais são insuficientes para a tomada de decisão que interfere em um grupo. É necessária uma análise mais profunda de todas as conexões existentes, sem uso do raciocino lógico individual. Em busca da solução comum ao grupo, procurou-se estabelecer um modelo de tomada de decisão que fosse: de construção simples; adaptável às diferentes empresas que formarão o grupo; intuitivo à interpretação e raciocínio dos integrantes; encorajador à formação de compromissos e consensos, para que o grupo possa evoluir; independente de especialização profunda para sua interpretação e comunicação; e de fácil reavaliação em seus detalhes.

\subsection{Seleção e classificação dos dados}

As empresas selecionadas para este estudo de caso são todas de pequeno porte, atuando em um mesmo segmento (equipamentos eletrônicos de pequeno porte), algumas concorrentes diretas entre si. O objetivo de se reunir empresas de mesmo porte, mesmo segmento e produtos similares, é o de facilitar a estruturação da rede, potencializando os ganhos das atividades similares, entre as quais:

- Compras conjuntas de componentes eletrônicos;

- Publicidade conjunta em veículos e semanários;

- Concentração da produção de itens comuns em um único fabricante, conforme a competência interna de cada um dos integrantes;

- Incentivo à transação comercial entre os integrantes; e 
- Formação de uma base sólida para o processo de absorção de novas tecnologias, estimulando a inovação tecnológica.

\subsubsection{Perfil das empresas integrantes}

As empresas selecionadas atuam em mercados diversos e são fabricantes dos produtos indicados na Tabela 3. Excetuando-se as empresas A e J, que contavam com mais de 100 colaboradores e que poderiam ser enquadradas em médias empresas para o segmento considerado, todas as demais contavam com 4 a 11 colaboradores, classificando-se como pequenas empresas.

Todas as empresas consideradas são de capital nacional e observou-se em todas que, o primeiro executivo e detentor de ferramentas decisórias é o próprio dono, o qual em muitos casos, executa também as atividades relacionadas à área comercial, à área de $\mathrm{P} \& \mathrm{D}$ e produção. Esta característica é mais acentuada quando a empresa trabalha sob encomenda.

\subsubsection{Integração atual e integração possível}

Observou-se que todos os empresários destas empresas conhecem os demais empresários considerados. Muitas vezes se conhecem até pessoalmente, mas a interação comercial entre suas empresas é praticamente inexistente. Porém, todos consideram viável a aproximação comercial, e apontaram várias possibilidades comerciais, tais como:

- Licenciamento de produtos: Uma das menores empresas integrantes demonstrou interesse na produção de alguns produtos já descontinuados da linha de produção de uma das duas maiores empresas integrantes;

- Compartilhamento de ferramentas: Uma das empresas detém uma ferramenta para injeção de gabinetes plásticos utilizados em instrumentos portáteis (multímetros, amperímetros, tacômetros etc.). Todas as demais compram este item de fabricantes locais ou importam. Há interesse na concentração da produção de gabinetes junto ao proprietá- rio da ferramenta; e

- Compartilhamento de horas-máquina: A maior empresa integrante da rede possui máquinas injetoras de termoplásticos, que permanecem paradas metade da jornada diária, em razão da sua baixa demanda. Há interesse deste e dos demais empresários na concentração de produção em um único local, otimizando a compra de resinas plásticas.

Estas possibilidades comerciais podem ser agregadas às oportunidades inicialmente previstas. O mapa atual de compartilhamento comercial e técnico é representado pela Figura 2.

Considerando-se a implantação da RCE, entre estas empresas, e em seu pleno funcionamento, o mapa de relacionamento comercial fica representado pela Figura 3.

Todo este relacionamento comercial poderá ocorrer paralelamente às demais atividades conjuntas, tais como compras, vendas, publicidade, conforme já citado anteriormente. Os dados apontados pelos empresários respondentes foram analisados e agrupados a fim de se começar a estruturação destes, conforme Tabela 4.

Os dados indicados na Tabela 4 indicam pontos em que há interesse em compartilhamento, ou não. Os dados foram agrupados com repetição de respostas, a fim de se avaliar os pesos de cada critério, no processo de hierarquização. A Tabela 5 indica os dados a serem utilizados na construção do modelo, para definição dos critérios de atuação do grupo.

\section{Construção do modelo}

Na construção do modelo é importante que se tenha idéia clara dos objetivos a serem atingidos e critérios a serem utilizados. Conforme proposto por Saaty (1991), o modelo foi construído a partir do objetivo principal, em direção aos critérios, com o maior detalhamento possível, conforme Figura 4.

Foi construída uma estrutura para benefícios e outra es-

Tabela 3. Linhas dos produtos principais e mercado de atuação mais intensiva.

\begin{tabular}{ccll}
\hline $\mathbf{N}^{\circ}$ & Emp. & Mercado de atuação & Principais Produtos \\
\hline 1 & A & Indústria em geral & Instrumentos e Controladores para painéis elétricos. \\
2 & B & Indústria em geral & Instrumentos e Controladores para painéis elétricos. \\
3 & C & Indústria de instrumentos de medição & Sensores digitais para instrumentos eletrônicos. \\
4 & D & Indústria e laboratórios especializados & Controladores de temperatura e sensores de pressão \\
5 & E & Indústria em geral & Instrumentos de medição e registradores gráficos. \\
6 & F & Indústria em geral & Controladores de vazão e temperatura.Velmotores. \\
7 & G & Distribuidoras de energia elétrica & Pressostatos e transmissores de pressão e nível. \\
8 & H & Construção civil & Terrômetros \\
9 & I & Indústria de equipamentos eletrônicos & Transformadores de corrente. Amperímetros. \\
10 & J & Indústria em geral & Multímetros digitais e sinalizadores sonoros. \\
11 & L & Indústria em geral & Instrumentos e Controladores para painéis elétricos. \\
12 & M & Indústria e laboratórios especializados & Instrumentos e controladores sob encomenda. \\
13 & N & Indústria e laboratórios especializados & Balanceador dinâmico digital, medidor de vibração. \\
14 & O & Indústria em geral e agropecuária & Instrumentos e controladores em geral. \\
\hline
\end{tabular}




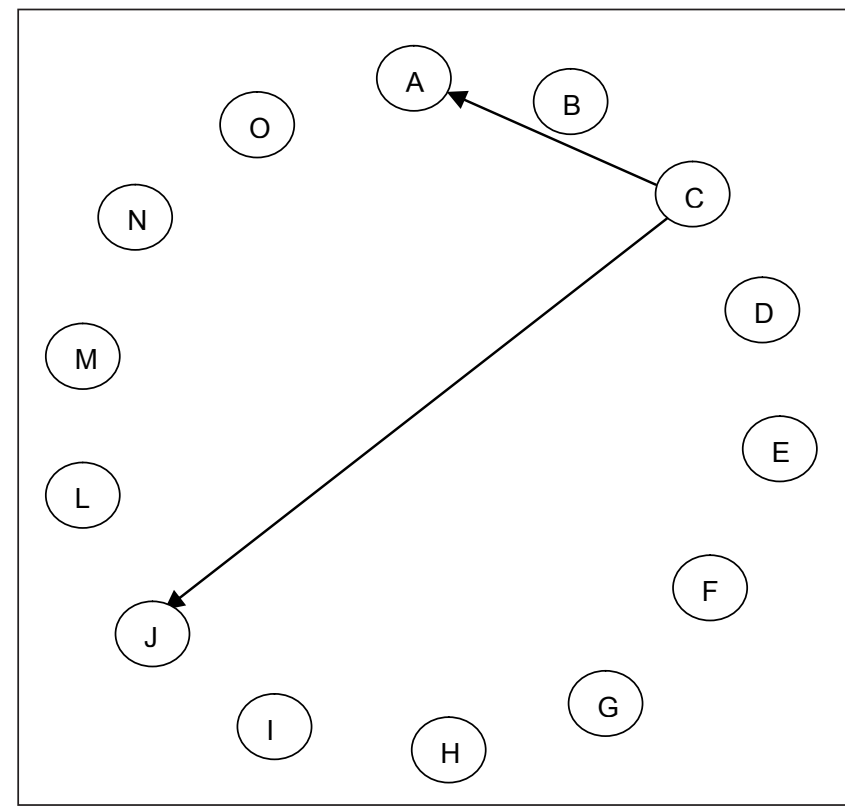

Figura 2. Mapa de relacionamento comercial entre os integrantes da RCE, antes da implantação.

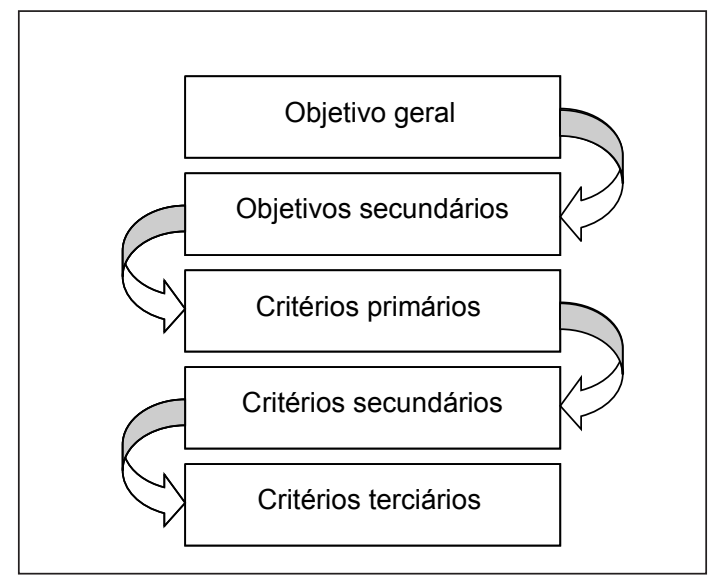

Figura 4. Estrutura geral do modelo de análise de hierarquia analítica.

trutura para os riscos, obedecendo aos níveis de desdobramento ilustrados na Figura 4. A hierarquia foi estabelecida de acordo com as seguintes etapas:

a) Identificação do objetivo global. Neste caso, o objetivo global das empresas é o aumento da lucratividade, o que estimulou a formação da rede. Este objetivo global será o mesmo para a hierarquia dos benefícios e dos custos;

b) Identificação dos objetivos secundários do objetivo global. Os objetivos secundários serão estabelecidos em função da análise e agrupamento das categorias dos itens em que há interesse de compartilhamento, indicados na Tabela 4. Também aqui, os objetivos secundários estabelecidos valerão para a hierarquia dos benefícios e dos riscos. Pode-se notar que os dados indicados na Tabela 4 estão agrupados em três categorias:

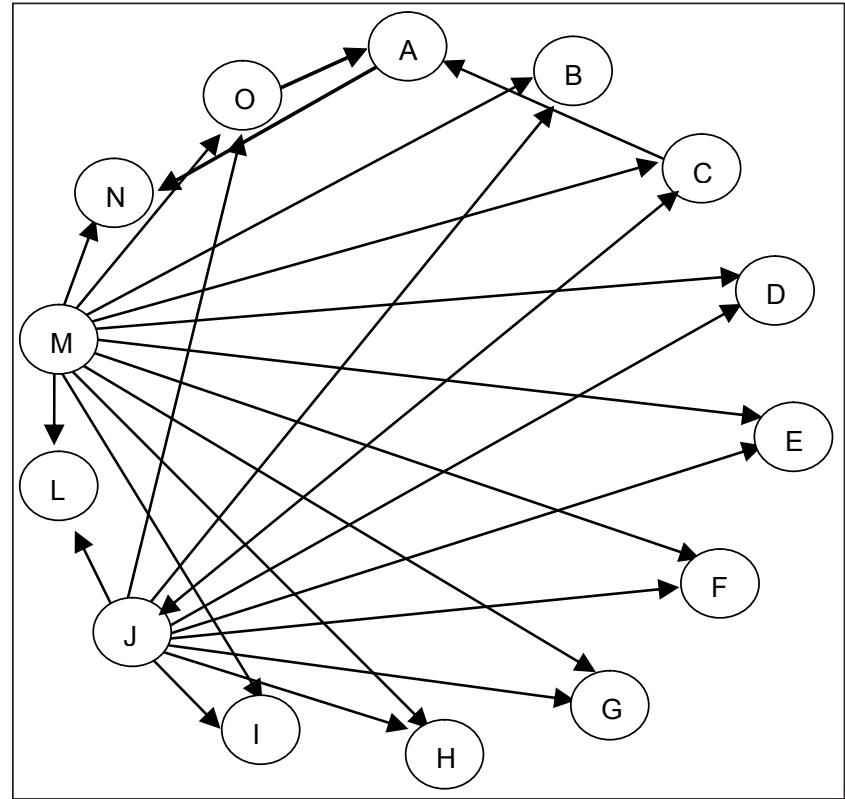

Figura 3. Mapa de relacionamento comercial possível após a implantação da RCE.

- Crescimento comercial no mercado interno;

- Exportação; e

- Redução de custos;

c) Estabelecimento dos critérios gerais que devem satisfazer aos objetivos secundários do objetivo global. Os critérios gerais serão os próprios dados indicados pelos empresários, na Tabela 4, utilizados na formulação dos objetivos secundários. Neste caso, os itens apontados como interessantes ao compartilhamento, comporão a hierarquia dos benefícios. Os itens em que foi apontado não interesse de compartilhamento serão integrantes da hierarquia dos riscos;

d) Identificação dos critérios secundários sob cada critério geral.Os critérios secundários serão estabelecidos a partir dos aspectos indicados pelos empresários, como Benefícios e Riscos, conforme apontado na Tabela 5. Neste caso, os critérios secundários indicados como Benefícios ou Riscos tanto poderá integrar a hierarquia dos Benefícios quanto a dos Riscos, conforme a avaliação dos critérios;

e) Avaliação da existência ou não de critérios terciários, os quais serão indicados a partir da análise do modelo como um todo, mesmo não tendo sido citados pelos empresários, mas desde que pertinentes à análise;

f) Identificação das opções ou resultados mais adequados.

g) Caso ocorram decisões do tipo sim/não, os benefícios decorrentes da aplicação da solução serão comparados aos benefícios da não aplicação da solução; e

h) Atribuição de valores aos objetivos, objetivos secundários e critérios. A atribuição dos valores numéricos é necessária para a avaliação do melhor custo/benefício dentre as diversas propostas. 
Tabela 4. Indicação dos pontos em que há e em que não há interesse de compartilhamento.

\begin{tabular}{ll}
\hline Há interesse em compartilhamento & Não há interesse em compartilhamento \\
\hline Compra/importação conjunta de componentes & Carteira de clientes \\
Compra/importação conjunta de componentes & Carteira de clientes \\
Compra/importação conjunta de componentes & Estrutura comercial \\
Compra/importação conjunta de matéria-prima & Feiras \\
Contratação conjunta de projetos & Informação técnica/segredos industriais \\
Desenvolvimento conjunto de ferramentas e moldes & Informação técnica/segredos industriais \\
Distribuição de produtos de terceiros & \\
Publicidade compartilhada & \\
Publicidade compartilhada & \\
Representantes comerciais & \\
Representantes no exterior & \\
Treinamento voltado à competitividade & \\
\hline
\end{tabular}

Tabela 5. Classificação de benefícios e Riscos apontados pelos empresários respondentes.

\begin{tabular}{ll}
\hline Benefícios & Riscos \\
\hline Acordos externos & Baixa capacidade fabril \\
Agilidade & Capacidade produtiva pequena \\
Ampla carteira de clientes & Capacidade produtiva pequena \\
Crescimento comercial & Dependência técnica \\
Desenvolvimento de software & Dificuldade de aquisição de matéria prima \\
Domínio técnico & Equipe de vendas tecnicamente fraca \\
Estoque de produtos acabados (pronta entrega) & Linha de produtos reduzida \\
Experiência & Pequena participação em feiras \\
Flexibilidade & Pequeno capital de giro \\
Grande variedade de produtos & Pouca exportação \\
Larga experiência & Pouca exportação \\
Qualidade & Poucos representantes \\
Rapidez na prototipagem & \\
\hline
\end{tabular}

\section{Atribuição de valores}

O ponto fundamental da construção do modelo é a quantificação dos aspectos mais importantes das hierarquias analíticas. Para a quantificação dos critérios, deve-se observar a freqüência com que o mesmo ocorre. Uma forma auxiliar de se quantificar os dados é por meio das seguintes questões:

- Quais são os critérios mais importantes?

- Quais são os objetivos mais importantes?

- Quais são as ações a serem colocadas em prática? e

- O que se deve planejar, e para obter quais resultados?

Além disso, deve-se avaliar cada aspecto sob o ponto de vista comum - da RCE, nunca sob o ponto de vista individual. Em seguida, os doze itens de compartilhamento indicados na Tabela 4 são utilizados na formação dos objetivos secundários, que constituirão o universo de pontuação. Como ocorreram oito respostas agrupadas em Redução de Custos, este objetivo secundário será pontuado com 0,666 (ou 66,6\%).

O mesmo raciocínio é aplicado a Crescimento Interno $(0,250)$ e Exportação $(0,084)$, com 3 e 1 respostas, respectivamente, conforme a Figura 5.

Em seguida, cada tipo de resposta específica, ainda na Tabela 4, no plano dos critérios primários, é quantificada de acordo com o número de vezes que aparece, totalizando a pontuação do respectivo objetivo secundário.

\section{Julgamentos}

O julgamento é utilizado para estabelecer a relação entre dois critérios, a fim de definir sua importância em relação aos objetivos secundários. Cada julgamento compara o domínio do elemento da coluna da esquerda com os elementos da linha superior. A pontuação é estabelecida pelos seguintes critérios:

- Qual dos dois elementos é mais importante para o objetivo principal?

- Com que intensidade o elemento da coluna da esquerda é 


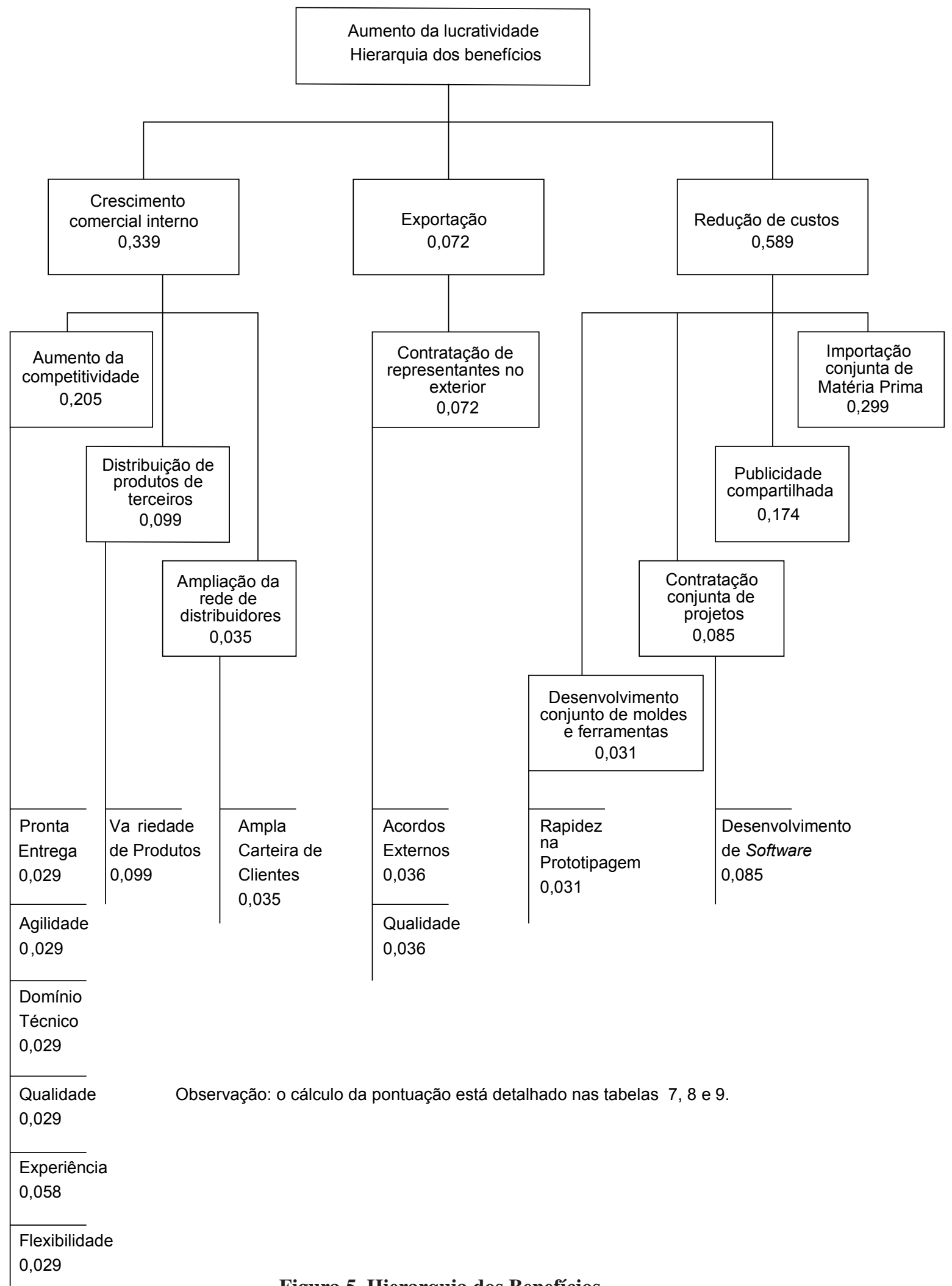

Figura 5. Hierarquia dos Benefícios.

mais importante que o elemento da linha? e

- Quando o elemento i for pontuado em um valor x (obtido da Tabela 6) em relação ao elemento j, este será pontuado em 1/x, quando comparado a i. É o que se denomina "pontuação reversa".
Os itens integrantes da hierarquia são colocados em uma matriz quadrada e pontuados entre si, de acordo com os pontos e características indicados na Tabela 6. A partir da pontuação calculam-se as prioridades de cada característica, conforme será visto a seguir. 


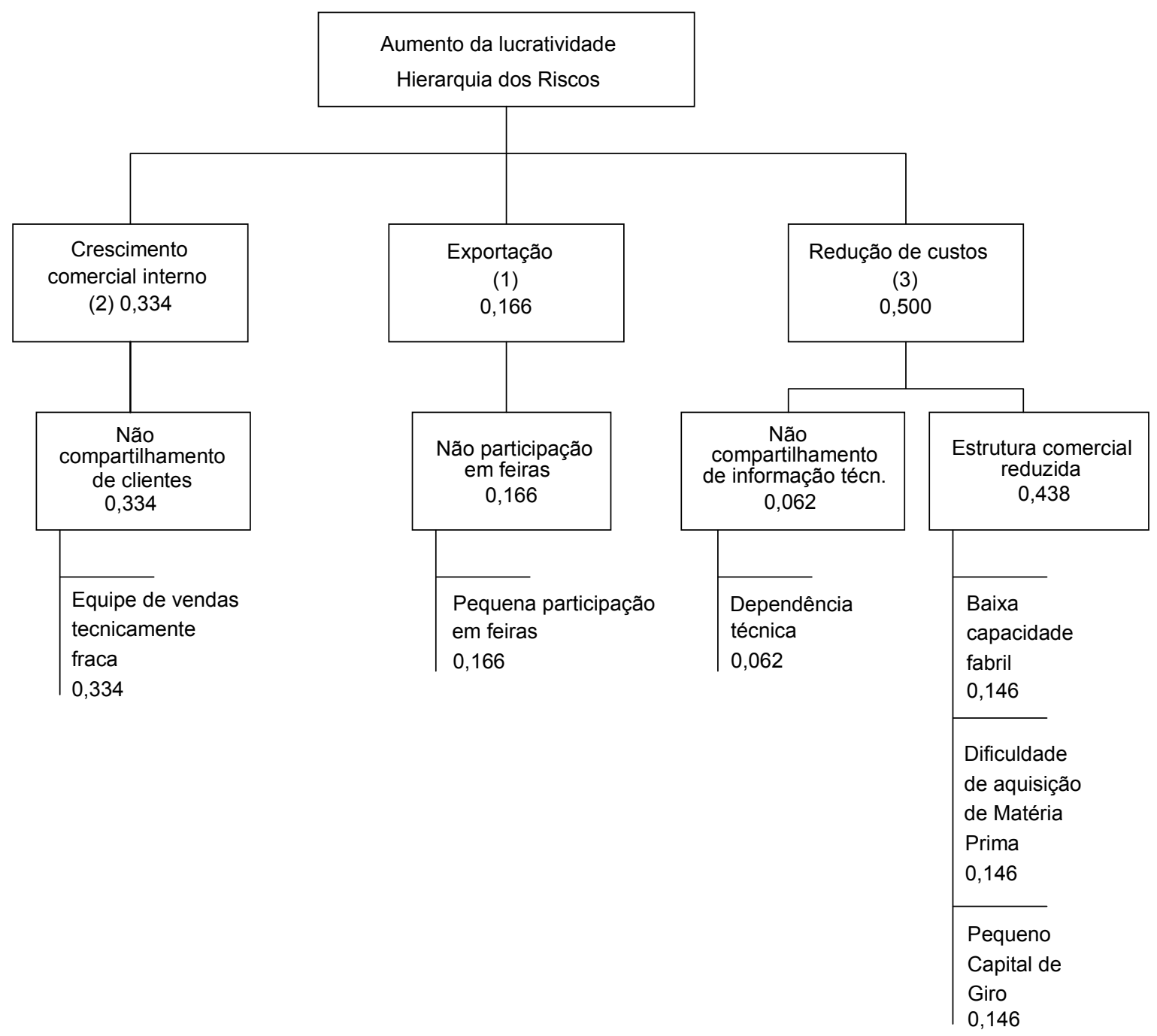

Figura 6. Hierarquia dos Riscos.

A primeira matriz compara par a par os objetivos secundários - crescimento comercial interno, exportação e redução de custos, conforme indicado na Tabela 7. A intensidade da importância destes objetivos secundários, face ao objetivo fundamental da RCE, foi obtida em dinâmica feita com todos os empresários, e que resultou no vetor de prioridades em destaque na Tabela 7. A prioridade de cada elemento é calculada a partir da respectiva coluna do elemento, ou seja, a prioridade do Crescimento Comercial Interno é calculada com os valores da coluna correspondente ao Crescimento Comercial Interno.

As matrizes de comparação e os respectivos vetores de prioridade são então feitos para o segundo nível da hierarquia e são apresentados nas Tabelas 8, 9 e 10.

Com as prioridades calculadas, determina-se a classificação de cada critério dentro do objetivo secundário (crescimento comercial interno), resultando em 0,205, 0,099 e 0,035 para os critérios aumento da competitividade, distribuição de terceiros e ampliação da rede de distribuidores, respectivamente.

A Tabela 9, completa a pontuação da Hierarquia de Benefícios, estabelecendo as prioridades do critério secundário da Redução de Custos.
Todas as pontuações resultantes das matrizes de prioridade estão indicadas na Figura 5, da Hierarquia dos Benefícios.

Finalizando este item, será feito o cálculo das prioridades da Hierarquia dos Riscos. Esta hierarquia será muito mais simples e reduzida que a Hierarquia dos Benefícios, dado o reduzido número de respostas indicadas nas Tabelas 2, 3, 4 e 5 .

É importante destacar que se compreende "Risco", nesta análise, como todo aspecto que possa introduzir conflitos dentro da formação da RCE, sendo encarado, portanto, como aspectos a serem evitados. Caso algum destes riscos possa comprometer o desenvolvimento cooperativo, este será discutido até sua compreensão e concordância, quanto à sua aplicação ou não, respeitando o justificado receio dos empresários participantes na condução do processo de cooperação.

Por outro lado, também se pode notar que alguns aspectos citados na Hierarquia dos Riscos aparecem como um item a ser trabalhado, no sentido de ser neutralizado como risco ou explorado como oportunidade. É o caso de "Dificuldade de Aquisição de Matéria Prima" que aparece em Riscos e também em Benefícios, como "Importação Conjunta de Matéria Prima", indicando uma oportunidade a ser explorada. 
Tabela 6. Pontuação para julgamento de objetivos e critérios.

\begin{tabular}{|c|c|c|}
\hline $\begin{array}{l}\text { Intensidade da } \\
\text { Importância }\end{array}$ & Definição & Explanação \\
\hline 1 & Igual importância & Duas atividades contribuem igualmente para a atividade. \\
\hline 3 & Importância moderada & Experiência e julgamento associam levemente uma atividade a outra. \\
\hline 5 & Forte importância & Experiência e julgamento associam fortemente uma atividade a outra. \\
\hline 7 & Importância muito forte ou comprovada & $\begin{array}{l}\text { Experiência e julgamento associam muito fortemente uma atividade } \\
\text { a outra. A dominação é comprovada na prática. }\end{array}$ \\
\hline 9 & Extrema importância & $\begin{array}{l}\text { A evidencia favorece uma atividade sobre outra. Há grande } \\
\text { possibilidade de se afirmar isto. }\end{array}$ \\
\hline $2 ; 4 ; 6 ; 8$ & Por compromisso entre os valores acima & $\begin{array}{l}\text { Às vezes deve-se interpolar o valor numérico do julgamento, porque não } \\
\text { há uma palavra adequada para a descrição. }\end{array}$ \\
\hline Recíprocos & $\begin{array}{l}\text { Se a atividade } \mathrm{i} \text { for pontuada com } x \text {, quando } \\
\text { comparada a atividade } \mathrm{j} \text {, então } \mathrm{j} \text { terá o valor } \\
\text { recíproco } 1 / x \text {, quando comparado a } \mathrm{i} \text {. }\end{array}$ & $\begin{array}{l}\text { Comparação necessária para escolher o elemento menor que a unidade, } \\
\text { a fim de estimar um número maior, como um múltiplo desta unidade. }\end{array}$ \\
\hline Racionais & Taxas obtidas na escala. & Se a consistência foi forçada para a obtenção de n valores, para montar a matriz. \\
\hline $1,1-1,9$ & Para atividades ligadas entre si. & $\begin{array}{l}\text { Quando os elementos são próximos e pouco distintos; moderado é } 1,3 \text { e } \\
\text { extremo é } 1,9 \text {. }\end{array}$ \\
\hline
\end{tabular}

Tabela 7. Matriz de julgamento das prioridades - Aumento da lucratividade.

\begin{tabular}{lccccc}
\hline Objetivo secundário & Crescimento comercial interno & Exportação & Redução de custos & Total & Prioridades \\
\hline Crescimento comercial interno & 1 & 5 & $1 / 3$ & 6,333 & 0,339 \\
Exportação & $1 / 5$ & 1 & $1 / 7$ & 1,343 & 0,072 \\
Redução de custos & 3 & 7 & 1 & 11 & 0,589 \\
\hline
\end{tabular}

Tabela 8. Matriz de julgamento das prioridades - Crescimento Comercial Interno.

\begin{tabular}{lcccc}
\hline Crescimento comercial interno & $\begin{array}{c}\text { Aumento da } \\
\text { competitividade }\end{array}$ & $\begin{array}{c}\text { Distribuição de produtos de } \\
\text { terceiros }\end{array}$ & $\begin{array}{c}\text { Ampliação da rede de } \\
\text { distribuidores }\end{array}$ & $\begin{array}{c}\text { Prioridades } \\
\text { Aumento da competitividade }\end{array}$ \\
Distribuição de produtos de terceiros & 1 & 3 & 5 & 0,605 \\
Ampliação da rede de distribuidores & $1 / 3$ & 1 & 3 & 0,291 \\
\hline
\end{tabular}

Tabela 9. Matriz de julgamento das prioridades - Redução de Custos.

\begin{tabular}{|c|c|c|c|c|c|}
\hline Redução de Custos & $\begin{array}{c}\text { Importação } \\
\text { conjunta de MP }\end{array}$ & $\begin{array}{c}\text { Publicidade } \\
\text { conjunta }\end{array}$ & $\begin{array}{l}\text { Contratação conjun- } \\
\text { ta de projetos }\end{array}$ & $\begin{array}{l}\text { Desenvolvimento } \\
\text { conjunto de moldes }\end{array}$ & Prioridades \\
\hline Importação conjunta de MP & 1 & 3 & 5 & 7 & 0,507 \\
\hline Publicidade conjunta & $1 / 3$ & 1 & 3 & 5 & 0,295 \\
\hline Contratação conjunta de projetos & $1 / 5$ & $1 / 3$ & 1 & 3 & 0,144 \\
\hline Desenvolvimento conjunto de moldes & $1 / 7$ & $1 / 5$ & $1 / 3$ & 1 & 0,053 \\
\hline
\end{tabular}

Tabela 10. Matriz para o objetivo secundário Redução de Custos - Hierarquia de Riscos.

\begin{tabular}{lccc}
\hline Redução de custos & Estrutura industrial reduzida & $\begin{array}{c}\text { Não compartilhamento de } \\
\text { informação técnica }\end{array}$ & Prioridades \\
\hline $\begin{array}{l}\text { Estrutura industrial reduzida } \\
\text { Não compartilhamento de }\end{array}$ & 1 & 7 & 0,875 \\
informação técnica & $1 / 7$ & 1 & 0,125 \\
\hline
\end{tabular}


Tabela 11. Escala de Prioridades para Benefícios e Custos.

Objetivo Primordial: Aumento da Lucratividade

\begin{tabular}{|c|c|c|c|}
\hline \multicolumn{4}{|c|}{ Objetivo Primordial: Aumento da Lucratividade } \\
\hline \multicolumn{2}{|r|}{ Hierarquia dos Benefícios } & \multicolumn{2}{|c|}{ Hierarquia dos Custos } \\
\hline Objetivos & Critérios & Objetivos & Critérios \\
\hline 1.Redução de custos & $\begin{array}{l}\text { 1.Importação conjunta de matéria prima } \\
\text { (componentes). }\end{array}$ & 1.Redução de custos & $\begin{array}{l}\text { 1. Estrutura comercial reduzida (a ser } \\
\text { neutralizado). } \\
\text { 2. Não compartilhamento de informações } \\
\text { técnicas (a ser aplicado). }\end{array}$ \\
\hline $\begin{array}{l}\text { 2. Crescimento comer- } \\
\text { cial interno. }\end{array}$ & 2. Publicidade Conjunta. & $\begin{array}{l}\text { 2. Crescimento } \\
\text { comercial interno. }\end{array}$ & $\begin{array}{l}\text { 3. Não compartilhamento de clientes } \\
\text { (a ser aplicado). }\end{array}$ \\
\hline \multirow[t]{6}{*}{ 3. Exportação. } & 3. Aumento da Competitividade (Cursos). & & \\
\hline & 4. Contratação conjunta de projetos. & & \\
\hline & 5. Contratação de representantes no exterior. & & \\
\hline & $\begin{array}{l}\text { 6. Desenvolvimento conjunto de } \\
\text { moldes e ferramentas. }\end{array}$ & 3. Exportação. & $\begin{array}{l}\text { 4. Não compartilhamento de feiras (a ser } \\
\text { aplicado e posteriormente avaliado). }\end{array}$ \\
\hline & 7. Distribuição de produtos de terceiros. & & \\
\hline & 8. Ampliação de rede de distribuição interna. & & \\
\hline
\end{tabular}

Os critérios que fazem parte do objetivo secundário, analisado na Tabela 10, serão pontuados igualmente, dada a similaridade existente entre eles (Baixa Capacidade Fabril, Dificuldade de Aquisição de Mão de Obra, Pequeno Capital de Giro).

\section{Resultados}

Com a pontuação das Hierarquias de Benefícios e Custos, é montada a Tabela 11.

A Tabela 11 indica os pontos de compartilhamento que apresentam mais benefícios e riscos. Serão avaliados também alguns aspectos que não apareceram diretamente neste levantamento, porém citados na reunião, como é o caso da utilização de um mesmo estojo plástico para alguns integrantes da RCE.

\section{Conclusão}

O estudo da formação desta RCE, segundo o modelo de Storper e Harrison (1991), permitiu identificar que, neste estágio inicial, ela caracteriza-se pela configuração do tipo rede sem assimetrias (all ring no core), sem a figura de uma empresa-líder, conforme idealizado pelo grupo.

A configuração observada, do tipo rede sem assimetrias, deu-se em função de um espírito de autodefesa das empresas integrantes, pois todas apresentam porte aproximado e mesma natureza de equipamentos fabricados, tornando a presença de qualquer tipo de hierarquia, um temor por parte dos empresários. Além disto, como o mercado almejado pelas empresas da RCE é o mesmo, é muito importante que o equilíbrio entre competição e cooperação seja mantido, conforme sugerido por Porter (1998). Para os empresários desta rede, observou-se uma aversão à presença de qualquer tipo de hierarquia, o que se deve, em parte, à falta de experiência anterior destes em- presários, nesta forma de organização, bem como o fato deste processo de projeto e inicio de operacionalização da rede ainda não ter permitido a construção de laços de confiança.

Os empresários argumentaram que a presença de hierarquia poderia acarretar um impacto reverso-negativo (negative reverse-impact), conforme Loebbecke e Van Fenema (1998), e, no caso da RCE projetada, buscou-se enfatizar as forças de sinergia, ou seja, a adição de valor pela troca de informação entre as partes envolvidas.

Dado este contexto, o método do AHP, que tem como característica ser um processo de tomada de decisão em equipe e que demanda consenso entre os decisores, tornou-se a ferramenta ideal para a definição dos objetivos da RCE, segundo uma configuração de rede sem assimetrias.

Além disto, é importante salientar que os dados identificados como prioritários, conforme o método AHP, foram coincidentes com os objetivos gerais do grupo, inclusive revelando objetivos que inicialmente não eram tão claros aos integrantes.

Houve aceitação geral dos resultados obtidos, tornando a aplicação deste método de Saaty (1991) adequado às etapas futuras, voltadas à consolidação da Rede de Cooperação Empresarial, tendo-se em vista que o AHP, conforme proposto por Saaty (1991), permite a estruturação dos objetivos comuns de um grupo de empresas de forma clara e minimizando a interferência de critérios pessoais. Sua aplicação ao processo de gestão da tecnologia comum, às pequenas e médias empresas em análise, permite uma abordagem criteriosa e objetiva, mesmo que, em um primeiro momento, esta análise possa parecer de simples elaboração.

A frequiência de interação nas atividades da RCE ainda não permitiu uma avaliação segundo o modelo de Belussi e Arcangeli (1998), demandando ainda investigações numa agenda futura de pesquisa. 
AL-SUBHI AL-HARBI, K.M. Application of the AHP in project management. International Journal of Project Management, n. 19, p. 19-27, Dhahran - Arábia Saudita, 1999.

BELUSSI, F.; ARCANGELI, F. A typology of networks: flexible and evolutionary firms. Research Policy, v. 27, p. 415428, 1998.

CARLSSON, Bo; JACOBSSON, S.; HOLMÉN, M.; RICKNE, A. Innovation systems: analytical and methodological issues. Research Policy v. 31, p. 233-245, 2002.

CARVALHO, M.M. QFD: uma ferramenta de tomada de decisão em projeto. 1997. Tese (Doutorado) Departamento de Engenharia Produção e Sistema, Universidade Federal de Santa Catarina, Florianópolis, 1997. Disponível em: <http:// www.eps.ufsc.br/teses97/marly/index.html>.

CARVALHO, M.M.; Laurindo, F.J.B. Estratégias para a competitividade. São Paulo: Ed. Futura, 2003. 272 p.

CARVALHO, M. M.; SERRA, N.; LAURINDO, F. J. B. Strategic Choices in Brazilian Textile \& Apparel Industries. In: EUROMA\&POMS2003 - EUROPEAN OPERATIONS MANAGEMENT ASSOCIATION \& PRODUCTION AND OPERATIONS MANAGEMENT SOCIETY - FIRST JOINT INTERNATIONAL CONFERENCE, 2003, Cernobbio. Proceedings of EurOMA\&POMS2003 - One world? One view of $O M$ ? The challenges of integrating research and practices, 2003. v. 1, p. 219-228.

DYER, J. S. A clarification of "Remarks on the Analytic Hierarchy Process". Management Science, v. 36, n. 3, p. 274275, Mar. 1990b.

Remarks on the Analytic Hierarchy Process. Management Science, v. 36, n. 3, p. 249-258, Mar. 1990a.

HUMPHREY, J; SCHMITZ, H. Governance and upgrading: linking industrial clusters and global value chain research. IDS Working Paper 120, p.1-37, 2000.

LAURINDO, F. J. B.; CARVALHO, M. M.; PESSÔA, M. S. P.; SHIMIZU, T. Selecionando uma aplicação de tecnologia da informação com enfoque na eficácia: um estudo de caso de um sistema para pcp. Gestão \& Produção, 2002.

LEVY, M.; LOEBBECKE, C.; POWELL, P. SMEs, Co-opetition and knowledge sharing:the role of information systems. European Journal of Information Systems 12, p. 3-17, 2003.

LOEBBECKE, C.; VAN FENEMA, P. (1998) Towards a Theory of Inter-organizational Knowledge Sharing during Coopetition. Proceedings of European Conference on IS, Aix-en-Provence.

LUNDVALL, B. A. Introduction. In: ed. National Systems of innovation: towards a theory of innovation and interactive learning. London: Pinter, 1992.

MORITA, H.; SHIMIZU, T.; LAURINDO, F. J. L. Modelos para estruturar e avaliar alternativas de decisão em Tecnologia da Informação. In: XIX ENEGEP - ENCONTRO NACIONAL DE ENGENHARIA DE PRODUÇÃO e V CONGRESSO INTERNACIONAL DE ENGENHARIA INDUSTRIAL. Anais, Rio de Janeiro, 1999. 1 CD-ROM

PORTER, M. Clusters and the new economics competitions. Harvard Business Review, p. 77-90, nov.-dec. 1998.

_ _; Stern, S. Innovation: Location Matters. MIT Sloan Management Review, summer, p. 28-36, 2001.

PRAHALAD, C.K; HAMEL, G. The Core Competence of the Corporation. Harvard Business Review, p. 79-91, May.Jun. 1990.

SAATY, T.L. An exposition of the AHP in reply to the paper "Remarks on the Analytic Hierarchy Process". Management Science, v. 36, n. 3, p. 259-268, Mar. 1990.

- How to make a decision - The Analitic Hierarchy Process. Interfaces, v. 24, n. 6, p.19-43, Pittsburgh, 1994.

SAATY, T.S. Método de Análise Hierárquica. São Paulo, McGraw-Hill, Makron, 1991

SEGENBERGER, W.; Pyke, F.Industrial districts and local economic regeneration: Research and policy issues". In: PYKE, F. et al. (1990) -. Geneva, International Labour Office, 1990.

STORPER, M.; HARRISON, B. Flexibility, hierarchy and regional developments: the changing structure of industrial production systems and their forms of governance in the 1990s. Research Policy, North-Holland, v. 20, n. 5, 1991.

WILLIAMSON, O. E. The Economic Institutions of Capitalism, Free Press, USA, 1985.

\section{SELECTING THE BASIC OBJECTIVES OF A BUSINESS COOPERATION NETWORK}

\section{Abstract}

The opening of global markets has led to a new economic order based essentially on competitiveness and technological innovation. New forms of industrial organization are rapidly incorporated into company culture in response to new market challenges. One of the most prominent forms of organization is the Business Cooperation Network-BCN. This paper analyzes the formation and configuration of a $B C N$ in the electric-electronic sector, highlighting the process whereby the businessmen of the BCN establish its basic objectives, whose priorities are structured using the Analytical Hierarchy Process (AHP) as a decision-making support tool. 